\title{
柱・梁接合部の破断危険度予測 \\ PREDICTION OF THE VULNERABILITY OF PREMATURE RUPTURE OF BEAM-TO-COLUMN CONNECTION
}

-Welded flanges and bolted web type-

\author{
加 藤 勉*
}

Ben KATO

\begin{abstract}
In the previous article, a design criterion to prevent the premature rupture of beam-end flange of beam-to-column moment resisting connection, in which beam flanges and web are both welded to the column face, was presented. In this paper, the maximum moment resistance and the plastic rotation capacity of the beam-to-column moment resisting connection, in which beam flanges are welded to column through the continuity plates and web is connected to column face by bolts, are analysed and a criterion to prevent the occurrence of connection rupture until the beam develops its own plastic rotation capacity is presented.
\end{abstract}

\section{Keywords : beam-to-column connection, stress transfer, plastic rotation capacity}

柱・梁接合部、応力伝達、塑性回転能力

\section{1. 序}

構造設計においては構造物全体および構造要素の耐力、塑性変形 能力に関して明確な要求性能が確立されていなければならない。こ れは柱・梁剛接合部（moment resisting connection）の設計につい ても例外でない。

文献 1 では梁端接合部の終局曲げ耐力は接合される梁固有の曲げ耐 力以上でなければならないという前提に立って、梁フランジ、ウェ ブ共に柱に直接溶接される接合部について、この前提をみたすため の条件式を提示した。これによって接合部の塑性回転能力を予測す ることが出来、従って設計で要求する塑性回転能力を発揮しうる接 合部を決定することが出来るのである。 本論文で扱う梁フランジは溶接、ウェブはボルト接合の柱・梁接合 部に対しても同じ原則を適用する。梁端においてフランジ、ウェブ 共に溶接という同条件の場合は接合端におけるウェブからフランジ への応力移行問題として一般的に論ずることができるが梁ウェブが 柱にボルト接合される場合はボルトの配置、数、径の組合せに自由 度があるので個別的なアプローチを必要とする。ボルト接合部が柱 面から離れた位置に設けられる場合（ブラケット方式）は本論文の 適用範囲外とする。

\section{2. 柱・梁接合部の保持すべき格局曲げモーメント}

序で述べた如く、接合部の終局曲げ耐力、jMu、は接合される梁 の固有の曲げ耐力以上であることが必要条件である。式で書けば、

$$
{ }_{j} M_{u} \geq S \cdot M_{p}
$$

$\mathrm{S}$ は局部座屈で決まる梁の最大曲げモーメントの全塑性モ一メント、 $\mathrm{Mp} 、 に$ 対する比で、 $\mathrm{S} \cdot \mathrm{Mp}$ が梁固有の最大曲げ耐力である。 $\mathrm{S}$ の值 および塑性率（塑性回転能力）、 $\eta$ 、は文献 2 . に与えられるが、本 論文で検証の対象となる実験はすべて鋼種 SN490 が用いられている ので、この鋼種についてのみ再録する。

$$
\mathrm{S}^{-1}=0.2868 \lambda_{\mathrm{f}}^{2}+0.0588 \lambda_{w}^{2}+0.7730
$$
但 $L 、 \mathrm{~S}^{-1} \geq \mathrm{Y}_{\mathrm{f}}$

(記号)

$\lambda_{\mathrm{f}}=\left(\frac{\mathrm{f} \sigma_{\mathrm{y}}}{\mathrm{E}}\right)^{1 / 2} \cdot \frac{\mathrm{b}}{\mathrm{t}_{\mathrm{f}}}:$ フランジの一般化細長比 $\lambda_{w}=\left(\frac{w}{E} \sigma_{y}\right)^{1 / 2} \cdot \frac{d e}{t_{w}}:$ ウェブの一般化細長比、梁の場合 $\mathrm{de}=\mathrm{d} / 2$ ${ }_{\mathrm{f}} \sigma_{\mathrm{y}}:$ フランジの降伏点、 ${ }_{\mathrm{w}} \sigma_{\mathrm{y}}$ : ウェブの降伏点、 $\mathrm{E}:$ ヤン グ係数、 $\mathrm{b}$ : フランジ幅の半分、 $\mathrm{d}:$ ウェブせい、 $\mathrm{t}_{\mathrm{f}}$ : フランジ 厚さ、 $\mathrm{t}_{\mathrm{w}}$ : ウェブ厚さ、 $\mathrm{Y}_{\mathrm{f}}={ }_{\mathrm{f}} \sigma_{\mathrm{y}} /{ }_{\mathrm{f}} \sigma_{\mathrm{u}}$ : フランジ材の降伏比、 ${ }_{\mathrm{f}} \sigma_{\mathrm{u}}:$ フランジの引張強さ (図 1 参照)

これに対応する部材角表示の梁の塑性回転能力、 $\eta$ 、は 


$$
\eta=\left(\frac{S-1}{2 S^{2}}\right)\left[\frac{E}{E_{s t}}(S-1)(2 S+1)+3(S+1)\left(\varepsilon_{p} / \varepsilon_{y}\right)\right] \cdots \cdots
$$

(記号) $\mathrm{E}_{\mathrm{st}}$ ：歪硬化保数、 $\varepsilon_{\mathrm{p}}$ : 歪硬化開始点の歪、 $\varepsilon_{\mathrm{y}}$ : 降伏歪 文献 1。に本章に関する詳細な記述がある。

\section{3. 梁端接合部の炵局曲げ耐力}

3.1 終局曲げ耐力の仮定

図 1 に示すような柱・梁接合部の終局曲け耐力、 $\mathrm{jMu、として} \mathrm{(4)}$ 式を仮定する。

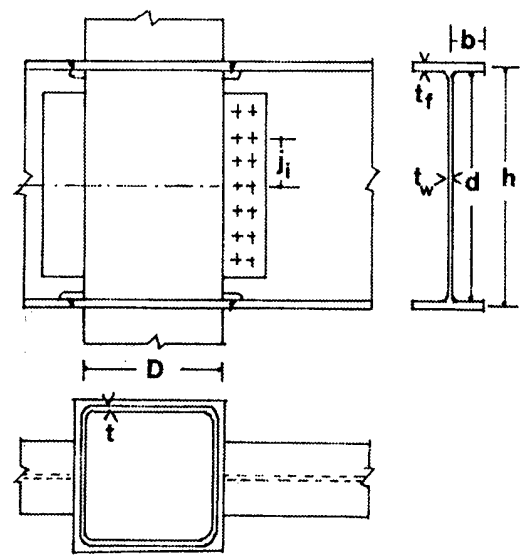

Fig 1. Beam-to-column connection

${ }_{j} M_{u}={ }_{f} M_{u}+{ }_{b} M_{u}$

(記号)

$$
\begin{aligned}
& { }_{\mathrm{f}} \mathrm{M}_{\mathrm{u}}=\mathrm{A}_{\mathrm{f}} \cdot \mathrm{h} \cdot{ }_{\mathrm{f}} \sigma_{\mathrm{u}}: \text { 梁フランジの最大曲げモーメント } \\
& \mathrm{A}_{\mathrm{f}}: \text { フランジ } 1 \text { 個の断面積 } \\
& \mathrm{h}: \mathrm{H} \text { 形断面梁のフランジ板厚中心間距離 } \\
& { }_{\mathrm{b}} \mathrm{M}_{\mathrm{u}}=\Sigma \mathrm{n} \cdot \mathrm{F} \cdot \mathrm{j}_{\mathrm{i}}: \text { 高カボルト群の最大曲げモーメント } \\
& \mathrm{F}: \text { 接合ボルト } 1 \text { 本の最大強さで下記のうち小さい方の值 } \\
& \quad \mathrm{F}=1.35 \sigma_{\mathrm{u}} \cdot{ }_{\mathrm{b}} \mathrm{A}: \text { 接合板の支圧強さ } \\
& \quad \mathrm{F}=\mathrm{f} / \sqrt{3} \cdot{ }_{\mathrm{s}} \mathrm{A}: \text { 高カボルトのせん断強さ } \\
& { }_{\mathrm{b}} \mathrm{A}=\mathrm{d} \cdot \mathrm{t}: \text { ボルト接触部の面積 } \\
& \mathrm{d} \quad: \text { ボルト軸径 } \\
& \mathrm{t} \text { : ウェブ又はガセットプレートの板厚 }
\end{aligned}
$$

$\sigma_{u}:$ ウェブ又はガセットプレートの引張強さ

$\sigma_{\mathrm{u}}{ }_{\mathrm{b}} \mathrm{A}$ はウェブ又はガセットプレートのいブれかが小さい方 の值をとる。

\section{${ }_{s} \mathrm{~A}:$ ボルトの軸断面積}

$\mathrm{f}_{\mathrm{u}}:$ 高力ボルトの引張強度

$\mathrm{j}_{\mathrm{i}}$ : ボルト群重心から $\mathrm{i}$ 番目のボルト迄の距離

$\mathrm{n}: \mathrm{j}_{\mathrm{i}}$ 位置のボルト数

${ }_{b} \mathrm{M}_{\mathrm{u}}$ の算定式はすべてのボルトが終局耐力に達していると仮定した もので、ボルト応力は水平方向に作用すると単純に仮定する。支圧 耐力式の係数 1.35 は建築学会、鋼構造限界状態設計規淮、6 章、6.3 によった。高力ボルトのせん断耐力は後述の実験において測定され ていないので、F10T のボルトの引張強度を $10 \mathrm{t} / \mathrm{cm}^{2}$ とし、せん断強 度を $10 / \sqrt{3}^{\mathrm{t} / \mathrm{cm}^{2}}$ とした。

材端接合部が終局耐力に達している状態であるから高力ボルトは当 然滑りを起こしており、支圧およびボルトのせん断で抵抗している。 ボルト接合部の面内剛性はウェブそのものの面内剛性より小さく、

\begin{tabular}{|c|c|c|c|c|c|c|c|c|c|c|c|c|c|}
\hline & \multicolumn{4}{|c|}{ proportion } & \multicolumn{8}{|c|}{ mechanical properties $\left(\mathrm{t}_{/} / \mathrm{cm}^{2}\right)$} & \\
\hline & $\mathrm{d} / \mathrm{h}$ & $\mathrm{b} / \mathrm{t}_{\mathrm{f}}$ & $d / t_{w}$ & $\mathrm{D} / \mathrm{t}$ & ${ }_{\mathrm{f}} \sigma_{\mathrm{y}}$ & ${ }_{w} \sigma_{\mathrm{y}}$ & ${ }_{f} \sigma_{u}$ & ${ }_{\mathrm{w}} \sigma_{\mathrm{u}}$ & $Y_{f}$ & $\mathrm{Y}_{\mathrm{w}}$ & $\frac{{ }^{w} \sigma_{y}}{{ }_{\mathrm{f}} \sigma_{y}}$ & $\frac{{ }_{w} \sigma_{u}}{{ }_{f} \sigma_{u}}$ & \\
\hline $\mathrm{R} 3$ & 0.96 & 5.0 & 44.3 & 23.7 & 3.78 & 4.33 & 5.27 & 5.64 & 0.72 & 0.77 & $1: 14$ & 1.07 & $\mathrm{RH}$ \\
\hline $\mathrm{R} 4$ & 0.97 & 6.2 & 47.5 & 15.9 & 3.95 & 4.34 & 5.65 & 5.76 & 0.70 & 0.75 & 1.10 & 1.02 & $\mathrm{RH}$ \\
\hline R5 & 0.96 & 4.9 & 49.1 & 20.4 & 3.60 & 4.04 & 5.10 & 5.36 & 0.71 & 0.75 & 1.12 & 1.05 & $\mathrm{RH}$ \\
\hline R6 & 0.96 & 5.3 & 38.5 & 11.7 & 3.49 & 3.38 & 5.28 & 5.09 & 0.66 & 0.66 & 0.97 & 0.96 & $\mathrm{BH}$ \\
\hline
\end{tabular}
ボルト穴と軸径間のクリアランス等もあるので、その回転剛性は低 下しており梁フランジとの変形適合は論じ難いが、終局においては 両者の和に達するものとして（4）式を仮定した。

\section{2 仮定終局曲げ耐力の妥当性}

予測式（4）の妥当性を検証するために既発表の実験値と比較した。 実験值は文献 $3 \sim 6$ に発表されたもので、夫々 R3、R4、R5、R6 と 略称する。 R3 では大阪大学、大阪工業大学担当の従来型接合部の結 果を用いた。 R6 ではボルト数、配置を変えている。 $\mathrm{R} 4$ R6 ではス カラップ形状を変化させている。梁の鋼種はすべて SN490、使用

Table 1. Outline of test specimens

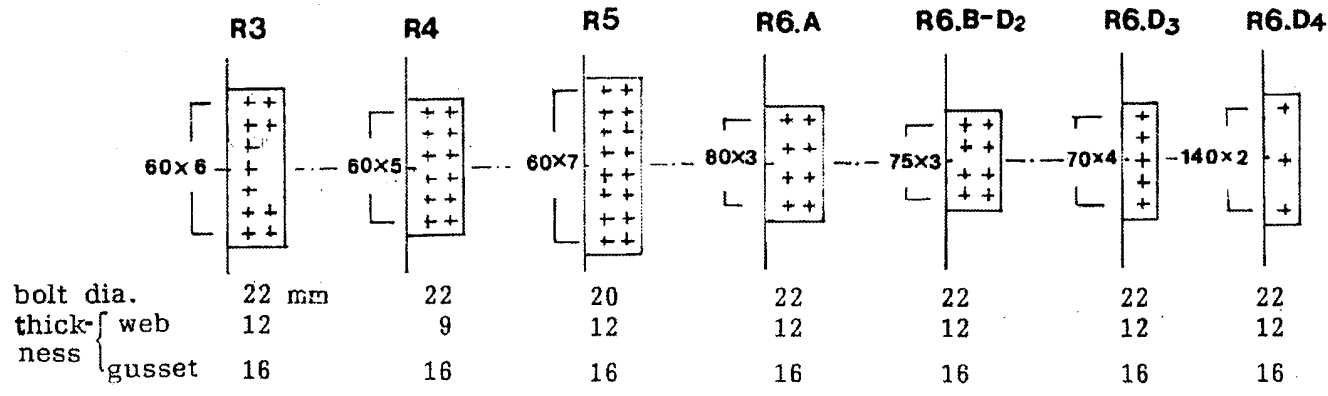

Fig 2. Details of bolted connection(in $\mathrm{mm}$ ) 
ボルトはF10Tで、試験体総数は 20 個である。

表 1 に梁の寸法、材料の強度特性を示す。

図 2 にボルト接合の詳細を示す。

夫々の試験体の（4）式による接合部終局曲げ耐力の計算值、 $\mathrm{jMu}$ 、

を表 2 に示す。ボルト 1 本の耐力、F、はすべて支圧で決まってい る。

表 3 に実験で得た各接合部最大曲げモーメント、 ${ }_{e} M_{u}$ 、その予測値、

${ }_{j} M_{u}$ 、に対する比、およびその他後章で述べる関連実験值を示す。

表 3 から $\mathrm{e} \mathrm{M}_{\mathrm{u}} / \mathrm{j}_{\mathrm{u}} \fallingdotseq 1$ であり、接合部の終局曲げ耐力は（4）式に

よって十分予測できることを示している。ウェブのモーメント奇与 率は柱面の幅厚比、D／t、にも影響される筈であるが、実験結果か らは有意の影響は見られなかった（表 1 に $\mathrm{D} / \mathrm{t}$ が記入されている。） これはボルト接合されたウェブの面内剛性が小さく、柱面の面外曲 げ剛性の大小にあまり影響されなかったものと考えられる。又、ス カラップ形状の影響も否定はできないが、接合部の全体挙動に大き な影響を与えていないようである。

\section{4. $\mathrm{M}_{\mathrm{p}}$ からの酎力上昇率、 $\mathrm{S}^{\prime}$}

文献 1 に述べた如く局部座屈で決まる梁断面の最大曲げ耐力の全塑 性モーメント、 $\mathrm{M}_{\mathrm{p}} 、$ からの上昇率、S、は（2）式で与えられるが、 この値は多数の研究者の実験結果を統計的に処理し、実用を意識し てやや保守的に査定したものであること、および、これらの実験は 材端無拘束の状態で行われたものであるが、柱・梁接合部の場合は 梁端フランジは柱ダイアフラムに溶接されて固定縁となるので座屈

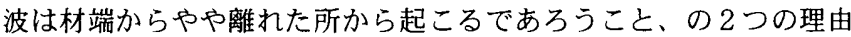
から柱・梁接合部近傍の応力上昇率、 $\mathrm{S}$ 、は（2）式の S より大き い可能性があるので、実験結果を用いて検討する。

即ち、材端における実際の応力上昇率 $\mathrm{S}^{\prime}={ }_{\mathrm{e}} \mathrm{M}_{\mathrm{u}} / \mathrm{M}_{\mathrm{p}}$ 、を計算し、 その（2）式の S に対する比、S'／S、を表 3 に示した。表に見る 如く $\mathrm{S}^{\prime} / \mathrm{S}$ は多少ばらつきが大きい。試験体の中には梁が十分局部 座屈耐力を発揮する前に材端破断に至ったものも含まれていること がその原因と考えられるが、当面 $\mathrm{S}^{\prime} / \mathrm{S} \leq 1$ となったもの（一印） を除外して残りの実験值の平均をとると 1.06 となるので、査定值と してこの值を用いる。

$$
\mathrm{S}^{\prime}=1.06 \mathrm{~S}
$$

\section{5. 塑性回転能力}

表 3 には塑性回転能力の赛測値 $\eta_{\mathrm{ex}}$ 、とその理論値、 $\eta(3$ 式)、に 対する比も示してある。これは次章で述べる判定式の妥当性の検証 に用いる。

\section{6. 材端破断先行防止のための条件式}

Table 2. Predicted joint maximum moment $($ in $\mathrm{tf} \cdot \mathrm{m}$ )

\begin{tabular}{|l|cccc|}
\hline & $\mathrm{F}(\mathrm{tf})$ & ${ }_{\mathrm{b}} \mathrm{M}_{\mathrm{u}}$ & ${ }_{\mathrm{f}} \mathrm{M}_{\mathrm{u}}$ & ${ }_{\mathrm{j}} \mathrm{M}_{\mathrm{u}}$ \\
\hline R3 & 20.77 & 27.42 & 189.26 & 216.68 \\
R4 & 15.40 & 16.63 & 44.94 & 61.57 \\
R5 & 17.65 & 30.71 & 201.51 & 232.22 \\
R6. A & 18.14 & 11.61 & 96.51 & 108.12 \\
R6. B D2 & 18.14 & 10.88 & 96.51 & 108.12 \\
R6. D3 & 18.14 & 7.62 & 96.51 & 104.13 \\
R6. D4 & 18.14 & 5.08 & 96.51 & 101.59 \\
\hline
\end{tabular}

Table 3. Test results

\begin{tabular}{|c|c|c|c|c|c|}
\hline & $\begin{array}{c}{ }_{e} \mathrm{M}_{\mathrm{u}} \\
(\mathrm{t} \cdot \mathrm{m})\end{array}$ & $\frac{{ }_{e} M_{u}}{{ }_{j} M_{u}}$ & $\frac{S^{\prime}}{S}$ & $\eta_{\mathrm{ex}}$ & $\frac{\eta_{\mathrm{ex}}}{\eta}$ \\
\hline 1 & 224.52 & 1.036 & 1.067 & 6.59 & 0.868 \\
\hline 2 & 215.18 & 0.993 & 1.079 & 5.01 & 0.660 \\
\hline 3 & 215.58 & 0.995 & 1.074 & 5.59 & 0.737 \\
\hline 4 & 227.69 & 1.051 & - & - & - \\
\hline 5 & 221.93 & 1.024 & 1.057 & 7.46 & 0.983 \\
\hline 6 & 212.90 & 0.983 & 1.016 & 5.75 & 0.758 \\
\hline 7 & 224.32 & 1.035 & 1.057 & 7.71 & 1.016 \\
\hline 8 & 233.16 & 1.076 & 1.085 & 7.20 & 0.949 \\
\hline av. & & & 1.062 & & 0.853 \\
\hline \multicolumn{6}{|c|}{ R4. $\quad \mathrm{S}=1.160, \quad \eta=5.43$} \\
\hline 9 & 62.70 & 1.018 & 1.101 & 6.00 & 1.105 \\
\hline 10 & 62.07 & 1.008 & 1.091 & 6.69 & 1.232 \\
\hline av. & & & 1.096 & & 1.168 \\
\hline \multicolumn{6}{|c|}{ R5 $\quad \mathrm{S}=1.172, \quad \eta=6.87$} \\
\hline 11 & 244.40 & 1.052 & 1.118 & 6.88 & 1.001 \\
\hline 12 & 224.76 & 0.968 & 1.028 & 6.98 & 1.016 \\
\hline av. & & & 1.073 & & 1.009 \\
\hline \multicolumn{6}{|c|}{ R6 $\quad \mathrm{S}=1.218 \quad \eta=7.63$} \\
\hline A.13 & 106.17 & 0.982 & 1.02 & 3.50 & 0.459 \\
\hline B. 14 & 104.21 & 0.970 & - & - & - \\
\hline C.15 & 106.76 & 0.994 & 1.026 & 3.85 & 0.505 \\
\hline D.16 & 106.56 & 0.992 & 1.024 & 3.40 & 0.446 \\
\hline E.17 & 110.29 & 1.027 & 1.059 & 3.85 & 0.505 \\
\hline $\mathrm{D}_{2} .18$ & 110.29 & 1.027 & 1.059 & 4.31 & 0.565 \\
\hline $\mathrm{D}_{3} .19$ & 109.50 & 1.051 & 1.053 & 4.18 & 0.548 \\
\hline $\mathrm{D}_{4} \cdot 20$ & 104.60 & 1.029 & - & - & - \\
\hline
\end{tabular}

以上で（1）式における ${ }_{j} M_{u}$ および $S^{\prime}$ の実態が判ったので (4)、 （5）式を（1）式に導入して、梁がその固有の曲げ耐力を発揮す る以前に材端破断を起こさない為の条件式を誘導する。

（4）、（5）式を（1）式に入れると、 


$$
{ }_{\mathrm{f}} \mathrm{M}_{\mathrm{u}}+{ }_{\mathrm{b}} \mathrm{M}_{\mathrm{u}}>1.06 \mathrm{SM}_{\mathrm{p}}
$$

(記号)

$$
\begin{aligned}
& \mathrm{M}_{\mathrm{p}}=\mathrm{A}_{\mathrm{f}} \cdot \mathrm{h} \cdot{ }_{\mathrm{f}} \sigma_{\mathrm{y}}+\frac{1}{4} \mathrm{~A}_{\mathrm{w}} \cdot \mathrm{d} \cdot{ }_{\mathrm{w}} \sigma_{\mathrm{y}}: \mathrm{H} \text { 形断面の全塑性モーメント } \\
& \mathrm{A}_{\mathrm{w}}=\mathrm{d} \cdot \mathrm{t}_{\mathrm{w}}: \text { ウエブの断面積 }
\end{aligned}
$$

（6）式を断面寸法、材料の機械的性質を用いて表すと

$$
{ }_{b} M_{u}>A_{f} \cdot h \cdot{ }_{f} \sigma_{u}\left\{1.06 S Y_{f}\left[1+\frac{1}{4} k\left(\frac{d}{n}\right)\left(\frac{{ }_{w} \sigma_{y}}{{ }_{f} \sigma_{y}}\right)\right]-1\right\}, \quad k=A_{w} / A_{f}
$$

表 1 に見る如く $\mathrm{d} / \mathrm{h}$ の値はサイズによらずほぼ一定値で平均値は 0.963 である。又圧延 $H$ 形鋼では $\frac{w \sigma_{y}}{{ }_{\mathrm{f}} \sigma_{y}}$ も大きな変動は無く平均值は 1.12 となっている。これに対し溶接集成 $\mathrm{H}$ 形鋼では、フランジとウ エブの降伏点は独立で許容範囲内でランダムに変動し得る。 R 6 で は 0.97 と小さい值となっているが 1 例にすぎないので当面圧延 $\mathrm{H}$ 形鋼の值 $\left(\frac{\mathrm{d}}{\mathrm{n}}\right)\left(\frac{\mathrm{w} \sigma_{\mathrm{y}}}{{ }_{\mathrm{f}} \sigma_{\mathrm{y}}}\right)=0.963 \times 1.12=1.078$ を用いることにすると上 式は、

$$
{ }_{b} \mathrm{M}_{\mathrm{u}}>\mathrm{A}_{\mathrm{f}} \cdot \mathrm{h} \cdot{ }_{\mathrm{f}} \sigma_{\mathrm{u}}\left[1.06 \mathrm{~S} \mathrm{Y}_{\mathrm{f}}(1+0.27 \mathrm{k})-1\right]
$$

となる。（7）式が梁固有の最大曲げモーメント、塑性回転能力を発 揮し得るか否かの判定規準となる。

念の為記号の説明を再記する。

${ }_{\mathrm{b}} \mathrm{M}_{\mathrm{u}}=\Sigma \mathrm{n} \cdot \mathrm{F} \cdot \mathrm{j}_{\mathrm{i}}$ : 高力ボルト群の最大曲げモーメント(3.1 参照)

$\mathrm{A}_{\mathrm{f}}$ : フランジ 1 個の断面積、 $\mathrm{A}_{\mathrm{w}}$ : ウェブの断面積、 $\mathrm{k}=\mathrm{A}_{\mathrm{w}} / \mathrm{A}_{\mathrm{f}}$ $\mathrm{h}: \mathrm{H}$ 形断面のフランジ板厚中心間距離、

${ }_{\mathrm{f}} \sigma_{\mathrm{u}}$ : フランジ材の引張強度、 $\mathrm{S}:$ （2）式の与える応力上昇率、 $\mathrm{Y}_{\mathrm{f}}={ }_{\mathrm{f}} \sigma_{\mathrm{y}} / \mathrm{f}_{\mathrm{f}} \sigma_{\mathrm{u}}:$ フランジ材の降伏比、

（7）式の妥当性を検証するために（7）式を

$$
1>\frac{{ }_{\mathrm{f}} \mathrm{M}_{\mathrm{u}}}{{ }_{\mathrm{b}} \mathrm{M}_{\mathrm{u}}}\left[1.06 \mathrm{~S} \mathrm{Y}_{\mathrm{f}}(1+0.27 \mathrm{k})-1\right]
$$

の形に変形し、右辺を安全指標（safety index）と呼ぶことにし、試 験体各グループの安全指標と実測塑性回転能力の（3）式の理論値 に対する比、 $\eta_{\mathrm{ex}} / \eta$ 、を対応させると表 4 のようになる。

$n_{\mathrm{ex}}$ は各グループの平均値をとった。 $\mathrm{R} 6$ 中 B から $\mathrm{D}_{2}$ 迄は同一形状 の試験体なのでその平均をとり、他は個別の值をとった。各グルー プ中、 $\mathrm{R} 4$ とR 5 が (7)' 式に適合しており、 $\eta_{\mathrm{ex}} / \eta$ も 1 を上回 っている。

両者の関係を図示すると図 3 のようになり、安全指標の増大と共に 接合部の回転能力が梁固有の回転能力から低下してゆくことが判る。

Table4. Safety index vs. rotation relation

\begin{tabular}{|c|cccccc|}
\hline & $\mathrm{R} 3$ & $\mathrm{R} 4$ & $\mathrm{R} 5$ & $\mathrm{R} 6(\mathrm{~A})$ & $\mathrm{R} 6\left(\mathrm{~B} \sim \mathrm{D}_{2}\right)$ & $\mathrm{R} 6\left(\mathrm{D}_{3}\right)$ \\
\hline index & 1.11 & 0.94 & 0.99 & 1.56 & 1.67 & 2.38 \\
$\eta_{\mathrm{ex}} / \eta$ & 0.85 & 1.17 & 1.01 & 0.46 & 0.50 & 0.55 \\
\hline
\end{tabular}

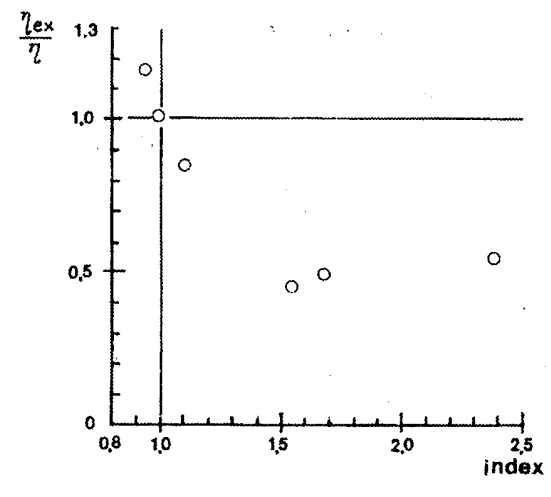

Fig $3 . \quad \eta_{\mathrm{ex}} / \eta$ vs. safety index relation

\section{7. 結}

1）梁固有の塑性回転能力を発揮する前に接合部破断を起こさせな い為には（7）式を満足する必要がある。

2) 幅厚比の大きい梁断面を用いればSの值が小さくなり、（7）式 を満足させ易くなるが、Sが小さくなるので（2）式に示すよ うに梁自身の塑性回転能力が小さくなる。従って設計の順序と しては、最初に設計上要求される梁の塑性回転能力に応じて (2)、（3）式より梁の断面形を設定し（幅厚比制限）、そのS を用いて（7）式を満足するようにボルト配置を決めることに なる。

3）ボルト径、ボルト本数を変化させた実験デー夕は少ないので、 判定式の信頼性を高めるには、この種の資料の蓄積が望まれる。

4) フランジ、ウェブ共に溶接の場合（文献 1 ）と同様、判定式 (7) を適用するに当たっては予め使用する鋼材の正確な機械的性質 を知っておく必要がある。降伏比として JIS 規定の上限值を用 いると極めて保守的な設計を強いられることになる。

\section{引用文献}

1. 加藤勉、柱 ·梁接合部の破断危険度予測、日本建築学会、構造系論文集、 P.155 160，2000年 1 月

2. 加藤勉、中尾雅躬、局部座居に支配されるH形断面銿部材の耐力と変形能 力、日本建築学会構造系論文集、第 458 号、P.127 136、1994 年 4 月

3. 通しダイアフラム形式で角形鋼管柱に接合される $\mathrm{H}$ 形鋼梁の望性変形能 力に関する実大実験報告書、3.4(大阪大学、大坂工業大学担当分)、P.102 ～127、日本建築学会近幾支部鉄骨棈造部会、1997 年 7 月

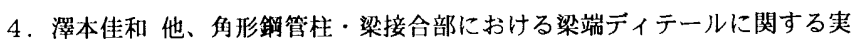
験的研究、日本建築学会大会学術潇演梗概集、P.375 376、1998 年 9 月

5. 宇佐美徽 他、スカラップとウェプ接合形式が梁の塑性変形能力に及ぼす 影響について、日本建築学会大会学術講演梗概集、P.353～354、1998 年 9 月 6. 寺風勝 他、混合接合形式の觕形鋼管柱· $\mathrm{H}$ 形鋼梁接合部における力学的 举動(その 1，2)、日本建築学会大会学術講演梗概集、P.1473〜 1476、1994 作 9 月 